\title{
Optimization of denaturing high performance liquid chromatography technique for rapid detection and identification of acetic acid bacteria of interest in vinegar production
}

\author{
Noelia Isabel Sagarzazu, Maribel Martínez, Cristina Algarra, Javier Butrón, \\ Carlos J. González-Navarro, Raquel Virto \\ Centro Nacional de Tecnología y Seguridad Alimentaria, Navarra, Spain
}

\begin{abstract}
This paper evaluates the use of denaturing high performance liquid chromatography (DHPLC) technology for the discrimination of genetic differences in the 16S rRNA and alcohol dehydrogenase (AdhA) genes among bacterial species based on its efficiency and sensitivity to enable the detection and discrimination of different genetic sequences. In order to optimize DHPLC protocols for the analysis of 16S rRNA gene fragments amplified from bacteria, DNA isolated from 22 different strains representing main bacterial groups of interest in food microbiology was analyzed. While the use of 16S rRNA gene did not allow to difference two wild strains of Acetobacter malorum, this region revealed as useful to differentiate them from some pathogenic bacteria as Escherichia coli, Salmonella typhimurium, Listeria monocytogenes, Listeria innocua, Clostridium perfringens or Sthapylococcus aureus, from spoilage microorganisms as Xantomonas vesicatoria and
\end{abstract}

Correspondence: Noelia Isabel Sagarzazu, Centro Nacional de Tecnología y Seguridad Alimentaria, 31570 San Adrián, Navarra, Spain.

Tel. +34.948670159 - Fax: +34.948696127 .

E-mail: nsagarzazu@cnta.es

Key words: Acetobacter, Gluconobacter, acetic acid bacteria, denaturing high performance liquid chromatography, vinegar production.

Acknowledgements: the authors thank Navarra Government for the support.

Conference presentation: part of this paper was presented at the $3^{\text {rd }}$ International Conference on Acetic Acid Bacteria. Vinegar and Other products, 2012 Apr 17-20, Cordoba, Spain (http://www.uco.es/aab2012/).

Contributions: NIS, MM, CA, JB have been mainly involved in the experimental work. NIS, RV, CJG-N have designed the experimental work, discussed the results, wrote the manuscript and coordinated the whole work.

Conflict of interests: the authors declare no potential conflict of interests.

Received for publication: 6 August 2012.

Revision received: 21 September 2012.

Accepted for publication: 27 November 2012

This work is licensed under a Creative Commons Attribution 3.0 License (by-nc 3.0).

(C) Copyright N. Isabel Sagarzazu et al., 2013

Licensee PAGEPress, Italy

Acetic Acid Bacteria 2013; 2(s1):e5

doi:10.4081/aab.2013.s1.e5
Alicyclobacillus spp., and also from lactic acid bacteria as Lactobacillus plantarum, Lactobacillus casei, Lactobacillus sakei, Lactobacillus acidophilus, Streptococcus thermophilus and Lactococcus lactis that may suppose technological risk during vinegar production. The results demonstrate that $16 \mathrm{~S}$ rRNA gene region is not adequate for the discrimination of the acetic acid bacteria (AAB) strains, so AdhA gene was selected to identify the two wild strains of Acetobacter malorum. Also 6 different reference strains of AAB were separated based on differences in AdhA gene region. DHPLC technology is able to discriminate between these two wild strains of $\mathrm{A}$. malorum based on differences existing in the AdhA gene region. The data obtained indicate that the technique is capable of identifying most bacteria at species level and even at strain level with optimization of the protocols. This is of particular relevance in the case of AAB due to their poor recovery on culture media and difficulties in detection of viable but non cultivable cells.

\section{Introduction}

Acetic acid bacteria (AAB) are microorganisms responsible for the transformation of ethanol into acetic acid. Nevertheless, not all the strains of a certain species have the same ability to carry out this oxidation. ${ }^{1}$ Therefore, it is important to discriminate among AAB strains during a fermentation process to determine how many strains are involved and which one is leading the process. Several types of vinegars are produced worldwide, differing in raw material, technologies (e.g. traditional and submerged methods of production) and use. ${ }^{2}$ The oxidation process is started by seed-vinegar, the so-called mother of vinegar that is a microbiologically undefined starter culture obtained from previous vinegar. The possibility of selecting strains with interesting properties to be used as new starter cultures may lead to an improved fermentation process. Optimization of desirable strain properties and elimination of undesirable microbial side effects are not possible in fermentations with wild unknown cultures.

Nowadays thirteen AAB genera are recognized: Acetobacter, Gluconobacter, Gluconacetobacter, Acidomonas, Asaia, Neoasaia, Granulibacter, Tanticharoemia, Ameyamaea, Kozakia, Saccharibacter, Swaminathania and Neokomagataea. There are studies that relate the presence of Acetobacter pasterianus to the production of vinegars with a low acid content ${ }^{3-5}$ and the presence of Gluconacetobacter species (Ga. xylinus, Ga. europaeus, Ga. oboediens and Ga. intermedius) to high acidity industrials vinegars. ${ }^{6,7}$ In traditional balsamic vinegar, which can be considered to be a mild-acidity vinegar, A. pasteurianus, $G a$. europaeus and $G a$. xylinus are the main species. ${ }^{8-10}$ The greatest limits to study and select $\mathrm{AAB}$ are due to difficulties in their isolation and cultivation. This is especially true for those strains isolated from 
sources with a high concentration of acetic acid, ${ }^{9-11}$ since they adapt to the extreme media. These cultivable problems have been associated to the absence of a suitable culture medium and the inability to detect viable but non cultivable (VBNC) cells by culture methods. ${ }^{12,13}$ For this reason, culture-independent methods, as the application of molecular methods, based on the identification/characterization of specific DNA segments, could be a proper solution for quick and accurate identification of these microorganisms. AAB have been identified by DNA-rRNA hybridization, DNA-DNA hybridization and ribosomal RNA gene sequences (5S rRNA, $16 \mathrm{~S}$ rRNA and $23 \mathrm{~S}$ rRNA) as well as AdhA gene sequences. $^{14,15}$

Denaturing high performance liquid chromatography (DHPLC) is used in a wide variety of genetic applications and most recently, a new application for this technique has been introduced: the identification of bacteria. Protocols for DHPLC - originally developed for mutation analysis $^{16-17}$ - were adapted for the separation of polymerase chain reaction (PCR)-amplified bacterial $16 \mathrm{~S}$ rRNA gene fragments. PCRamplified fragments are subjected to a column containing polystyrene/polydivinylbenzene particles. The separation of the PCR products is based on the elution of partially melted DNA molecules by the reagent triethylamonium acetate (TEAA). Bacterial DNA samples with internal sequence variations and melting domains display differences in retention times. There are some key factors to successful detection of bacterial genetic variants in DHPLC: PCR primer design, PCR protocol, separation gradient and temperature. ${ }^{18}$

This technique is a well documented culture-independent method for analysis of microbial communities in environmental and food samples such as intestinal flora, ${ }^{19}$ urinary tract infections, ${ }^{20}$ cheese and dairy products, ${ }^{21}$ endodontic infections ${ }^{22}$ and soil. ${ }^{23}$ It has been used as an efficient diagnostic method for rapid identification of foodborne pathogens in food matrixes. ${ }^{24}$ Other authors ${ }^{21}$ showed, for the first time, the use of the DHPLC analysis to profile a food-related mixed microbial community. Compared to current techniques of bacterial identification, DHPLC is quick, economical and capable of screening large numbers of samples in a relatively short period of time. ${ }^{25}$

DHPLC is used in this study to discriminate genetic differences in the 16S rRNA and alcohol dehydrogenase (AdhA) (subunit I of PQQdependent $\mathrm{ADH}$ ) genes among bacterial species based on its efficiency and sensitivity to enable the detection and discrimination of different genetic sequences.

\section{Materials and Methods}

\section{Microorganisms}

Strains from Salmonella typhimurium (CECT 878), Listeria monocytogenes (CECT 4032), Listeria innocua (CECT 910), Escherichia coli (CECT 8110), Staphylococcus aureus (CECT 976), Xantomonas vesicatoria (CECT 792), Alicyclobacillus spp. (CECT 5137), Lactobacillus casei (CECT 475), Lactobacillus acidophilus (CECT 903), Clostridium perfringens (CECT 486), Lactococcus lactis (CECT 539), Streptococcus thermophilus (CECT 801), Acetobacter aceti (DSM 3508), Acetobacter pasteurianus (DSM 3509), Acetobacter malorum (DSM 14337), Gluconobacter cerinus (DSM 9533), Gluconacetobacter intermedius (DSM 11804) and Gluconacetobacer xylinus (DSM 2004) were used as reference strains. The microorganisms used in this investigation were supplied by the Spanish Type Culture Collection (CECT) and by the German Collection of Microorganisms and Cell Cultures (DSMZ). They were cultivated and preserved according to the DSMZ and CECT procedures. Two wild strains of Lactobacillus plantarum and Lactobacillus sakei isolated from a meat matrix, and two wild strains of Acetobacter malorum (wt1 and wt2) isolated from wine vinegar samples were also used. These wild strains were identificated by sequencing.

Broth subcultures of each strain were prepared in flasks containing $50 \mathrm{~mL}$ of tryptic soy broth (Biolife, Milan, Italy) plus $0.6 \%(\mathrm{w} / \mathrm{v})$ of yeast extract (Biolife) (TSBYE), MRS broth for lactic acid bacteria (Merck, Darmstadt, Germany) and YPM broth ( $0.5 \%$ yeast extract, $0.3 \%$ peptone, $2.5 \%$ mannitol) for AAB inoculated to an initial concentration of approximately $10^{6} \mathrm{CFU} / \mathrm{mL}$. The cultures were incubated under agitation (135 rpm) (mod. Rotabit, Selecta, Spain) at $30^{\circ} \mathrm{C}$ or $37^{\circ} \mathrm{C}$ for 24 or $48 \mathrm{~h}$ until the stationary growth phase was reached (Table 1). Lactobacillus was incubated under anaerobiosis.

Wine vinegar was contaminated with different reference $\mathrm{AAB}$ strains (A. pasteurianus, Ga. xylinus and $\mathrm{G}$. cerinus). $10 \mathrm{~mL}$ of growth cultures $\left(10^{8}\right.$ colony forming unit $\left.\mathrm{mL}^{-1}\right)$ were centrifugated at $10,000 \mathrm{~g}$ for 10 $\mathrm{min}$, the pellet was resuspended in $3.33 \mathrm{~mL}$ and then they were mixed reaching a final volume of $10 \mathrm{~mL}$.

\section{DNA extraction}

Total DNA was isolated by phenol-chloroform extraction (ISO 21571:2005) from $1 \mathrm{~mL}$ of bacterial cultures or artificially contaminated vinegar samples. Samples were homogenized in $1 \mathrm{~mL}$ lysis buffer (500 mM Tris, pH 9.0, $20 \mathrm{mM}$ EDTA, $10 \mathrm{mM} \mathrm{NaCl}$ ) (Sigma-Aldrich, Munich, Germany) with $50 \mu \mathrm{L}$ lisozime $(10 \mathrm{mg} / \mathrm{mL})$ (Sigma-Aldrich) and were incubated $1 \mathrm{~h}$ at $37^{\circ} \mathrm{C}$. Then $25 \mu \mathrm{L}$ of proteinase $\mathrm{K}(20 \mathrm{mg} / \mathrm{mL})$ (Sigma-Aldrich) and $25 \mu \mathrm{L}$ of $1 \%$ sodium dodecyl sulfate (SigmaAldrich) were added and incubated at $10 \mathrm{~min} / 60^{\circ} \mathrm{C}$. One volume of isoamyl-phenol-chloroform (25:24:1) was added, the aqueous phase was transferred to a fresh sterile tube, and DNA was further purified by chloroform/isoamyl alcohol (24:1) extraction. After centrifugation at $13,000 \mathrm{~g}$ for $10 \mathrm{~min}$, the aqueous phase was transferred to a fresh sterile tube, and DNA was precipitated on ice with 0.1 volume of sodium acetate $(3 \mathrm{M})$ and 2.5 volumes of $99 \%(\mathrm{v} / \mathrm{v})$ ethanol (Panreac, Barcelona, Spain). After an additional centrifugation at 13,000 g for 20 min, the supernatant fluid was discarded. The DNA pellet was washed twice with $70 \%(\mathrm{v} / \mathrm{v})$ ethanol, air-dried, resuspended in $100 \mu \mathrm{L}$ of TrisEDTA buffer (10 mM Tris, $1 \mathrm{mM}$ EDTA, pH 8.0), and stored in a $-20^{\circ} \mathrm{C}$ freezer. Extraction of pure lysis buffer was performed in parallel as a negative control.

\section{Polymerase chain reaction conditions}

After several tests, the following optimized PCR conditions were used in a $50-\mu \mathrm{L}$ reaction for the amplification of the $16 \mathrm{~S}$ rRNA fragment: $1 \times$ PCR Buffer, $1.5 \mathrm{mM} \mathrm{MgCl}, 0.2 \mu \mathrm{M}$ of forward and reverse primer, $0.2 \mathrm{mM}$ of each dNTP, $1.25 \mathrm{U}$ of AmpliTaq Gold DNA polymerase (Applied Biosystems, Branchburg, NJ, USA), and $10 \mu \mathrm{L}$ of template containing 50-100 ng of extracted DNA. PCR was conducted in GeneAmp ${ }^{\circledR}$ PCR System 9700 Thermal Cycler (Applied Biosystems) with the following parameters: initial denaturation at $95^{\circ} \mathrm{C}$ for $10 \mathrm{~min} ; 25$ cycles of denaturation at $94^{\circ} \mathrm{C}$ for $1 \mathrm{~min}$, annealing at $66^{\circ} \mathrm{C}$ for $30 \mathrm{~s}$ and extension at $72^{\circ} \mathrm{C}$ for $30 \mathrm{~s}$; final extension at $72^{\circ} \mathrm{C}$ for $10 \mathrm{~min}$. The oligonucleotide primers used for the amplification were those described by Domann et al. ${ }^{26}$ Forward (5'-GCACAAGCGGTGGAGCATGTGG-3') and Reverse (5'-GACGGGCGGTGTACAAG-3'). An amplicon size of 474 bp was obtained.

For the amplification of the AdhA fragment the following conditions were used: $1 \times$ PCR Buffer, $1.5 \mathrm{mM} \mathrm{MgCl} 2,0.5 \mu \mathrm{M}$ of forward and reverse primer, $0.2 \mathrm{mM}$ of each dNTP, $1.25 \mathrm{U}$ of AmpliTaq Gold DNA polymerase (Applied Biosystems), and $5 \mu \mathrm{L}$ of template containing 50-100 ng of extracted DNA. PCR was conducted in GeneAmp ${ }^{\circledR}$ PCR System 9700 Thermal Cycler (Applied Biosystems) with the following parameters: initial denaturation at $95^{\circ} \mathrm{C}$ for $10 \mathrm{~min} ; 45$ cycles of denaturation at $94^{\circ} \mathrm{C}$ for $30 \mathrm{~s}$, annealing at $60^{\circ} \mathrm{C}$ for $1 \mathrm{~min}$ and extension at $72^{\circ} \mathrm{C}$ for 1 min; final extension at $72^{\circ} \mathrm{C}$ for $7 \mathrm{~min}$. The PCR products were electrophoresed in $2 \% \mathrm{w} / \mathrm{v}$ agarose gels using $1 \times$ Tris acetate running 
buffer. The oligonucleotide primers used for the amplification of the AdhA fragment were those described by Trcek: ${ }^{15}$ ADHforward (5' - TGGYWCGGCATTCCGGG-3') degenerated and ADHreverse (5'-GTVGCGTCRTARGCRTGGAA-3). An amplicon size of 377 bp was obtained.

\section{Denaturing high performance liquid chromatography conditions}

PCR amplifications were analyzed by DHPLC using a WAVE ${ }^{\circledR}$ DNA Fragment Analysis System (Transgenomic, Omaha, NE, USA) equipped with DNASep ${ }^{\circledR}$ cartridge (Transgenomic). Chromatography was performed using a two eluent buffer system. Buffer A consisted of an aqueous solution of 0.1 M TEAA, pH 7.0, and buffer B consisted of an aqueous solution of $0.1 \mathrm{M}$ TEAA, $\mathrm{pH} 7.0$, with $25 \%$ (v/v) acetonitrile. Chromatograms were recorded using a UV detector at a wavelength of $260 \mathrm{~nm}$. As it is previously said, the elution of DNA fragments in the system was influenced by essential factors such as column temperature, pump flow rate, gradient rate of buffer $\mathrm{B}$, and time of elution. The following conditions were investigated: column temperatures of 50 $70^{\circ} \mathrm{C}$, buffer B gradient rates of $35-65 \pm 5 \%$, gradient B loading of $1-5 \%$, elution durations of 5-30 min, and pump flow rates of 0.4-0.9 $\mathrm{mL} \mathrm{min}^{-1}$. All buffers and solutions were obtained from Transgenomic Company at analytical grade. Different gradient protocols used in this research are described in Tables 1-3. Each experiment was performed at least three times on separate days to value the reproducibility of the technique.

\section{DNA sequencing and sequences}

Direct sequencing of the purified PCR products was performed by the Sanger Method ${ }^{27}$ using dideoxynucleotides (ddNTPs) (Stratagene, CA, USA). PCR products were verified by agarose gel electrophoresis and cleaned up with the NucleoSpin columns (Macherey Nagel $\mathrm{GmbH}$, Dueren, Germany). The cleaned PCR products were sequenced by the automatic sequencer ABI PRISM 310 (Applied Biosystems). Sequence comparisons were done using BLAST ${ }^{28}$ at the DNA Data Bank GeneBank (www.ncbi.nlm.nih.gov/genbank) and aligned using the ClustalW2 algorithm (www.ebi.ac.uk).

\section{Results and Discussion}

\section{Optimization of denaturing high performance liquid chromatography parameters for the molecular analy- sis of bacteria}

In order to optimize DHPLC protocols for the analysis of 16S rRNA gene fragments amplified from bacteria, PCR amplifications from different strains representing main bacterial groups of interest in food microbiology was analyzed (L. monocytogenes, L. innocua, E. coli, $S$. aureus, S. typhimurium, C. prefringens, $X$. vesicatoria, Alyciclobacillus spp, L. plantarum, L. sakei, L. casei, L.acidophilus, S. thermophilus, $L$. lactis, A. malorum). Among these selected strains there are pathogens, spoilage microorganisms, lactic acid bacteria and AAB. Variation of technical DHPLC parameters (acetonitrile gradient, column temperature and flow rate) resulted in a protocol that allowed effective and reproducible characterization of $16 \mathrm{~S}$ rRNA gene amplicons from these groups of bacteria (Table 1). To compare the retention time, these 14 species were individually analyzed using DHPLC. Amplicons containing 16S rRNA gene fragments were identified due to their different retention times ranging from 5 to $11 \mathrm{~min}$ (Figure $1 \mathrm{~A}$ and $\mathrm{B}$ ). As in the DHPLC system the column temperature plays a significant role in partial denaturation of DNA molecules allowing discrimination and characterization of DNA fragments of microbial population, the optimal column temperature was investigated using PCR products of different bacterial species. At higher temperatures, DNA fragments become partially denatured, which lead to the reduction in the double-stranded portion of the PCR fragments: the greater the reduction of the doublestranded state, the faster the elution of the sample. The retention time differences are attributed to the reduced negative charges in the single-stranded portions of the molecule compared to the double-stranded molecule. ${ }^{18}$ Positively charged ammonium ions of TEAA interact more favorably with the negatively charged phosphate ions of the doublestranded DNA molecules allowing more adsorption or retention to the stationary phase in the cartridge. Therefore, a gel-like separation of DNA fragments with different base pair sequences is achieved without a gel. While the use of $16 \mathrm{~S}$ rRNA gene did not allow to difference the two wild strains of $A$. malorum, this region revealed as useful to differentiate them from some pathogenic bacteria as E. coli, S. typhimurium, L. monocytogeenes, L. innocua, C. perfringens or S. aureus (Figure 1A), from spoilage microorganisms as $X$. vesicatoria and Alicyclobacillus spp., and also from lactic acid bacteria as L. plantarum, L. casei, L. sakei, L. acidophilus, S. thermophilus and L. lactis (Figure 1B). Some of them may suppose technological risks during vinegar production. For example, $X$. vesicatoria is known to be the cause of serious disease in fruits (grapes) and different substrates utilized in vinegar production as tomato. ${ }^{29}$ Alicyclobacillus has been possed as a challenge for the microbial stability of juices worldwide. ${ }^{30}$ During industrial wine-making, the development of lactic acid bacteria can occur during alcoholic fermentation or even during storage or ageing causing changes in the wine composition that can alter its quality. ${ }^{31}$ Using this molecular technique may do an analysis of the raw material for vinegar production in order to identify possible manufacture problems.

Table 1. Strains and growth conditions used.

\begin{tabular}{lcccc} 
Name & $\begin{array}{c}\text { Growth } \\
\text { medium }\end{array}$ & $\begin{array}{c}\text { Growth } \\
\text { temperature }\end{array}$ & $\begin{array}{l}\text { Incubation } \\
\text { time }\end{array}$ & Code \\
S. typhimurium & TSBYE & $37^{\circ} \mathrm{C}$ & $24 \mathrm{~h}$ & 1 \\
L. monocytogenes & TSBYE & $37^{\circ} \mathrm{C}$ & $24 \mathrm{~h}$ & 2 \\
\hline L. innocua & TSBYE & $37^{\circ} \mathrm{C}$ & $24 \mathrm{~h}$ & 3 \\
E. coli & TSBYE & $37^{\circ} \mathrm{C}$ & $24 \mathrm{~h}$ & 4 \\
\hline S. aureus & TSBYE & $37^{\circ} \mathrm{C}$ & $24 \mathrm{~h}$ & 5 \\
X. vesicatoria & TSBYE & $37^{\circ} \mathrm{C}$ & $24 \mathrm{~h}$ & 6 \\
\hline Alicyclobacillus spp. & TSBYE & $37^{\circ} \mathrm{C}$ & $24 \mathrm{~h}$ & 7 \\
L. casei & MRS & $37^{\circ} \mathrm{C}$ & $24 \mathrm{~h}$ & 8 \\
\hline L. acidophilus & MRS & $37^{\circ} \mathrm{C}$ & $24 \mathrm{~h}$ & 9 \\
C. perfringens & TSBYE & $37^{\circ} \mathrm{C}$ & $24 \mathrm{~h}$ & 10 \\
\hline L. lactis & MRS & $37^{\circ} \mathrm{C}$ & $24 \mathrm{~h}$ & 11 \\
S. thermophilus & MRS & $37^{\circ} \mathrm{C}$ & $48 \mathrm{~h}$ & 12 \\
\hline A. aceti & YPM & $30^{\circ} \mathrm{C}$ & $72 \mathrm{~h}$ & 13 \\
A. pasteurianus & YPM & $30^{\circ} \mathrm{C}$ & $72 \mathrm{~h}$ & 14 \\
\hline A. malorum & YPM & $30^{\circ} \mathrm{C}$ & $72 \mathrm{~h}$ & 15 \\
G. cerinus & YPM & $30^{\circ} \mathrm{C}$ & $72 \mathrm{~h}$ & 16 \\
\hline Ga. intermedius & YPM & $30^{\circ} \mathrm{C}$ & $72 \mathrm{~h}$ & 17 \\
Ga.xylinus & YPM & $30^{\circ} \mathrm{C}$ & $72 \mathrm{~h}$ & 18 \\
\hline L. plantarum & MRS & $37^{\circ} \mathrm{C}$ & $24 \mathrm{~h}$ & 19 \\
L. sakei & MRS & $37^{\circ} \mathrm{C}$ & $24 \mathrm{~h}$ & 20 \\
\hline A. malorum wt1 & YPM & $30^{\circ} \mathrm{C}$ & $72 \mathrm{~h}$ & 21 \\
A. malorum wt2 & YPM & $30^{\circ} \mathrm{C}$ & $72 \mathrm{~h}$ & 22 \\
\hline . & & & \\
\hline
\end{tabular}

TSBYE, tryptic soy broth yeast extract; MRS, Man, Rogosa and Sharpe agar; YPM, yeast extract peptone mannitol. 
Application of denaturing high performance liquid chromatography for analysis of acetic acid bacteria from vinegar samples: detection of $A$. malorum with primer targeting AdhA

Another gene target was searched in order to identify wild strains of A. malorum. The phylogenetic positions of the AAB species were commonly established on the basis of $16 \mathrm{~S}$ rRNA genes. However, the pairwise comparison among the $16 \mathrm{~S}$ rRNA gene sequences shows a very high similarity (93.7-99.9\%) in AAB. The 16S-23S rRNA gene internal transcribed spacer (ITS) region sequences of $\mathrm{AAB}$ exhibit lower nucleotide similarity (60.7-88.0\%) than the $16 \mathrm{~S}$ rRNA gene sequences. ${ }^{32-35}$ The analysis of partial AdhA sequences showed that this region is more discriminative for AAB species differentiation than 16S-23S rDNA regions. ${ }^{15}$ Therefore, the suitability of gene encoding subunit I of PQQ-dependent AdhA as a target gene for molecular analysis of $A A B$ was analyzed. The results of this study confirmed those of previous reports demonstrating that $16 \mathrm{~S}$ rRNA gene region is not adequate for the discrimination of the $A A B$ strains from the same species, ${ }^{15}$ so AdhA gene was selected to identify the two wild strains of $A$. malorum.

The alignment of two partial AdhA sequences of $377 \mathrm{bp}$ from wild strains of $A$. malorum wt1 and wt2 showed a high similarity with only three base pair differences between strains (data not shown). Trcek ${ }^{15}$

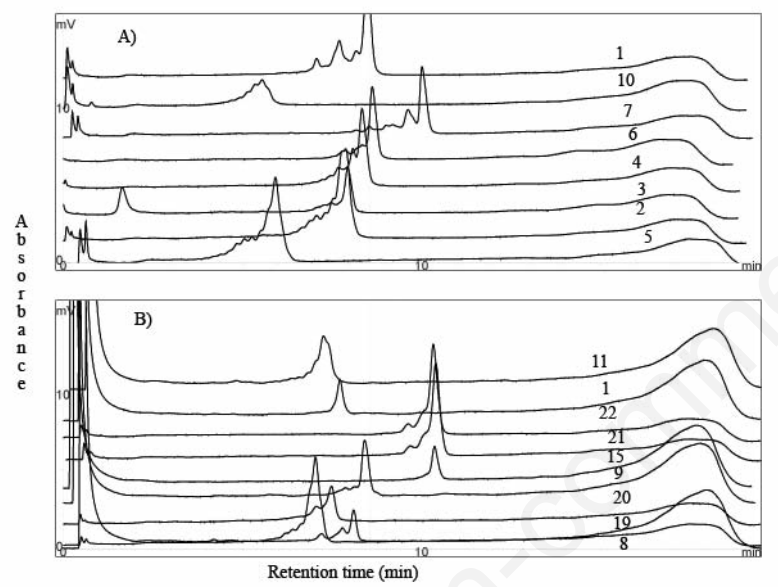

Figure 1. Chromatograms representing the analysis of different bacterial species using optimized polymerase chain reaction and denaturing high performance liquid chromatography conditions (16S rRNA gene region, conditions of Table 2). Peaks shown represent strains corresponding with codes $1,2,3,4,5,6,7$, and 10 (A) 1, 8, 9, 11, 15, 19, 20, 21 and 22 (B).

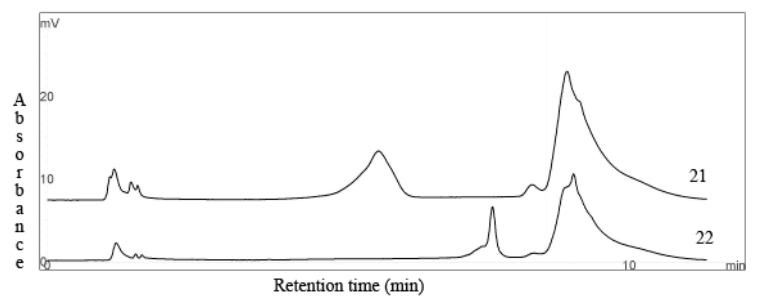

Figure 2. Chromatogram representing the analysis of two wild strains of A. malorum using optimized polymerase chain reaction and denaturing high performance liquid chromatography conditions (AdhA gene region, conditions of Table 3). has already reported the presence of conserved regions interspersed with variable segments distributed randomly over the sequence. This author also reported that the interspecies similarities varied from $58.9 \%$ to $67.5 \%$ between genera Acetobacter and Gluconacetobacter, from $66.3 \%$ to $75.5 \%$ between genera Acetobacter and Gluconobacter, and from $69.3 \%$ to 78.5\% between genera Gluconobacter and Gluconacetobacter. Moreover this author also found that the comparison of AdhA sequences among strains of $G a$. europaeus and $G a$. intermedius showed the lowest nucleotide substitution rate (100\% identity). Variation of technical DHPLC parameters (acetonitrile gradient, column temperature and flow rate) resulted in a protocol that allowed effective and reproducible characterization of AdhA gene amplicons from wild strains of A. malorum wt1 and wt2 (Table 3 ). As it can be observed in the chromatogram (Figure 2), DHPLC technology is able to discriminate between these two wild strains of $A$. malorum based on differences existing in the AdhA gene region.

\section{Optimization of denaturing high performance liquid} chromatography parameters for analysis of acetic acid bacteria in pure cultures and in a vinegar matrix

The genomic DNA of six AAB reference strains was extracted and subjected to analysis of PCR-DHPLC assay under optimal conditions (Tables 2-4) in order to achieve an adequate separation of the peaks

Table 2. Conditions for the analysis of bacterial species with the WAVE $^{\circledR}$ denaturing high performance liquid chromatography device.

\begin{tabular}{lccc} 
Gradient designation & Time ( $\mathrm{min})$ & Buffer A (\%) & Buffer B (\%) \\
\hline Loading & 0.0 & 51.0 & 49.0 \\
$100 \mathrm{bp}$ & 0.5 & 46.0 & 54.0 \\
\hline $225 \mathrm{bp}$ & 3.0 & 43.0 & 57.0 \\
$350 \mathrm{bp}$ & 6.5 & 40.0 & 60.0 \\
\hline $475 \mathrm{bp}$ & 12.5 & 35.0 & 65.0 \\
$600 \mathrm{bp}$ & 14.5 & 20.0 & 80.0 \\
\hline Start clean & 15.5 & 0.0 & 100 \\
Stop clean & 16.5 & 0.0 & 100 \\
\hline Start equilibrate & 17.0 & 51.0 & 49 \\
Stop equilibrate & 17.5 & 51.0 & 49
\end{tabular}

The program was performed at an oven temperature of $62.5^{\circ} \mathrm{C}$ and a flow rate of $0.9 \mathrm{~mL} / \mathrm{min}$. Amplicons were generated with primers designed by Doman ${ }^{26}$ for the amplification of the $16 \mathrm{~S}$ rRNA gene region.

Table 3. Conditions for the analysis of Acetobacter malorum wild strains with the WAVE ${ }^{\circledR}$ denaturing high performance liquid chromatography device.

\begin{tabular}{lccc} 
Gradient designation & Tlime (min) & Buffer A (\%) & Buffer B (\%) \\
Loading & 0.0 & 48.5 & 51.5 \\
$100 \mathrm{bp}$ & 1.0 & 42.0 & 58 \\
\hline $225 \mathrm{bp}$ & 2.5 & 39.5 & 60.5 \\
$350 \mathrm{bp}$ & 2.6 & 38.7 & 61.3 \\
\hline $475 \mathrm{bp}$ & 4.0 & 36.4 & 63.6 \\
$600 \mathrm{bp}$ & 5.0 & 34.4 & 65.6 \\
\hline Start clean & 5.9 & 0.0 & 100 \\
Stop clean & 6.0 & 0.0 & 100 \\
\hline Start equilibrate & 6.1 & 48.5 & 51.5 \\
Stop equilibrate & 6.9 & 48.5 & 51.5 \\
\hline
\end{tabular}

The program was performed at an oven temperature of $55^{\circ} \mathrm{C}$ and $64.6^{\circ} \mathrm{C}$ for A. malorum wt2 and wt respectively and a flow rate of $0.9 \mathrm{~mL} \mathrm{~min}-1$. Amplicons were generated with primers designed by $\operatorname{Trcek}^{15}$ for the amplification of the AdhA gene region. 
Table 4. Conditions for the analysis of acetic acid bacteria reference strains with the WAVE ${ }^{\circledR}$ denaturing high performance liquid chromatography device.

\begin{tabular}{|c|c|c|c|c|c|c|}
\hline \multirow[t]{2}{*}{ Gradient designation } & \multicolumn{2}{|c|}{ Time (min) } & \multicolumn{2}{|c|}{ Buffer A (\%) } & \multicolumn{2}{|c|}{ Buffer B (\%) } \\
\hline & A & B & A & B & A & B \\
\hline Loading & 0.0 & 0.0 & 48.4 & 65 & 51.6 & 35 \\
\hline Start gradient & 0.5 & 1.0 & 43.4 & 47 & 56.6 & 53 \\
\hline Stop gradient & 5.0 & 8.0 & 34.4 & 32 & 65.6 & 68 \\
\hline Start clean & 5.1 & 8.1 & 0.0 & 0.0 & 100 & 100 \\
\hline Stop clean & 5.6 & 9.1 & 0.0 & 0.0 & 100 & 100 \\
\hline Start equilibrate & 5.7 & 9.2 & 48.4 & 65 & 51.6 & 35 \\
\hline Stop equilibrate & 6.6 & 11.2 & 48.4 & 65 & 51.6 & 35 \\
\hline
\end{tabular}

The program was performed at an oven temperature of $64.5^{\circ} \mathrm{C}(4 \mathrm{~A})$ or $64.0^{\circ} \mathrm{C}(4 \mathrm{~B})$ and a flow rate of $0.9 \mathrm{~mL} \mathrm{~min}^{-1}$. Amplicons were generated with primers designed by Trcek ${ }^{15}$ for the amplification of the AdhA gene region.

corresponding to each strain. Amplicons of the $16 \mathrm{~S}$ rRNA and AdhA genes of pure cultures were generated via PCR and analyzed on the DHPLC system. In Figure 3, the different retention times of pure amplicons of A. malorum, A. aceti, A. pasteurianus, G. cerinus, Ga. intermedius and $G a$. xylinus are demonstrated when injected separately and in combination. The separation of amplicons derived from these strains can be clearly observed, as well as the reproducibility when injected together.

For the identification of $G a$. xylinus our results indicate that the $16 \mathrm{~S}$ rRNA gene region was the most suitable, as the peak corresponding to Ga. xylinus is clearly differentiated from the other five AAB (Figure $3 \mathrm{~A})$. These results suggest that the $16 \mathrm{~S}$ rRNA gene region in $\mathrm{Ga}$. xylinus differs notably from the five other AAB strains tested in this study. However, for these strains, the investigation of the same region has not allowed a right separation among them, due to the very high similarity (93.7-99.9 \%) of 16S rRNA gene sequences. Therefore, another gene target, the AdhA gene region, was analysed. As it has previously reported, this region is more discriminative for AAB species differentiation. ${ }^{15}$ DHPLC conditions were optimized testing various oven temperatures, flow rates and gradients. Finally, it was found the best work conditions for the separation of the five AAB reference strains (Table 4). It has been achieved an adequate separation among peaks corresponding to different bacteria, except in the case of $\mathrm{A}$. malorum and $\mathrm{Ga}$. intermedius, whose peaks are coincident in all the programs tested, due to a high similarity between their AdhA sequences. Ga. xylinus has not showed peaks for both AdhA optimized protocols (Figure 3B and C), suggesting that the AdhA gene region in $G a$. xylinus differs notably from the other five $A A B$ reference strains tested in this study. Under other DHPLC running protocols different peaks for Ga. xylinus AdhA amplicons have been obtained (data not shown).

DNA extracted from samples obtained by artificially contamination of white wine vinegar was amplified via PCR with the primer pair ADHforward/ADHreverse and subsequently applied to DHPLC using optimized running conditions as demonstrated above. The vinegar was contaminated with three reference strains: A. pasteurianus, $G$. cerinus and $G a$. xylinus. Genomic DNA of the vinegar was extracted and subjected to analysis of PCR multiplex-DHPLC assay under optimal conditions (Table 4) that allow the separation between A. pasteurianus and $G$. cerinus. As expected, $G a$. xylinus did not show peak under this DHPLC conditions (Figure 4)

Other authors have tried to identify and quantify the microbiota involved in vinegar production with culture-independent methods. Some studies have used denaturing gradient gel electrophoresis (DGGE) or temporal temperature gradient gel electrophoresis (TTGE) as culture independent alternative for $\mathrm{AAB}$ identification at the species level in different substrates. $4,8,36,37$ Other alternatives for identification and quantification of $\mathrm{AAB}$ are fluorescence in situ hybridisation
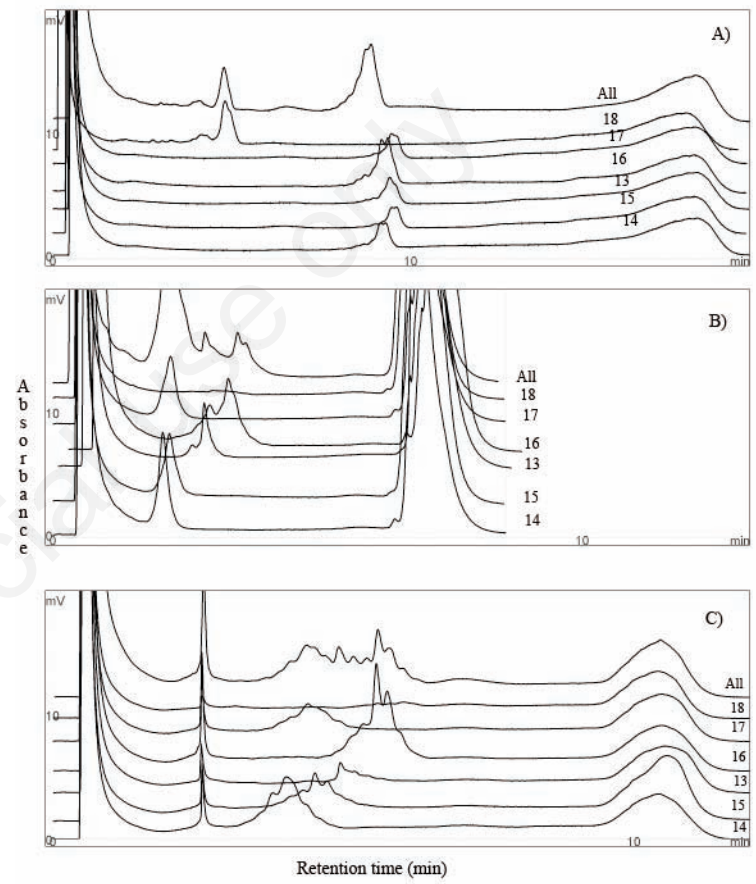

Figure 3. Chromatograms representing the analysis of six acetic acid bacteria reference strains using optimized polymerase chain reaction and denaturing high performance liquid chromatography conditions (A with conditions of Table 2, 16S rRNA gene region; $B$ with conditions of Table 4 , AdhA gene region; and $C$ with conditions of Table 4, AdhA gene region) Peaks shown represent strains corresponding with codes $13,14,15,16,17,18$ and a mix of all amplicons.

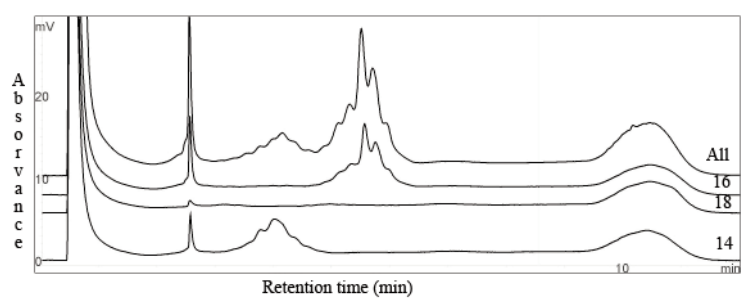

Figure 4. Chromatograms representing the analysis of contaminated vinegar with acetic acid bacteria reference strains using optimized polymerase chain reaction and denaturing high performance liquid chromatography conditions (AdhA gene region, conditions of Table 4). Peaks shown represent strains corresponding with codes 14, 16, 18 and a mix of all amplicons. 
(FISH), epifluorescence and real-time PCR. ${ }^{36,38-41}$ However, not always they can be considered sufficient to achieve a confident identification at species level. The high degree of homology among AAB species makes it difficult to design species-specific primers and probes. Therefore, because of their discriminating power, a possible alternative is to use DHPLC as a useful technique for differentiating among AAB species with high genetic similarity. The different intensities of peaks in DHPLC may reflect the relative abundance of populations as previously demonstrated by other authors. ${ }^{18}$ This is an advantage in monitoring bacterial populations of interest and allow to determine which ones are abundant or dominant, present or absent in acid acetic fermentation during vinegar production. DHPLC also allows fraction collection of peaks for DNA isolation and sequencing, which leads to bacterial identification and characterization of the bacterial community/ assemblage composition. By comparing the peak profile of an unknown sample of AAB with the peak profile of known species and strains previously obtained, the sample can be quickly and simply identified. The approach presented here was successfully used for identification and characterization of the $\mathrm{AAB}$ present in vinegar.

\section{Conclusions}

This work expands the capabilities of DHPLC technique for detection of genetic variations in bacteria. PCR-based DHPLC was successfully adapted for the analysis of more complex bacterial communities overcoming cultured-based approaches. DHPLC appears to be a promising technique for identifying and genetically characterizing bacteria at the molecular level without sequencing DNA. The data obtained indicate that the technique is capable of identifying most bacteria at the species level and even at the strain level with optimization of the protocols. This is of particular relevance in the case of $A A B$ due to the absence of a suitable culture medium and the inability to detect VBNC cells by culture methods.

Results obtained are preliminary and it is needed to analyze more bacterial species and strains to provide further insights in relation to differentiation and interaction of different species and closely related species or strains. Moreover, DHPLC diversity profiles could not necessarily reflect the true diversity in a complex sample. The limitations could be attributed to different factors not only conserved nature of selected genes but also DNA extraction inherent limitations, formation of chimera and heteroduplex, and preferential bias during the PCR. For this reason it is needed to optimize not only the DHPLC running conditions but also DNA extraction procedures, as well as PCR especially when it is necessary to analyze total DNA extracted from complex food matrix such as some special vinegar.

\section{References}

1. Gullo M, Giudici P. Acetic acid bacteria in traditional balsamic vinegar: phenotypic traits relevant for starter cultures selection. Int J Food Microbiol 2008;125:46-53.

2. Giudici P, Gullo M, Solieri L, et al. Gli aceti del mondo. In: Giudici P, Gullo M, Solieri L, et al., (Ed.). Le fermentazioni dell'aceto balsámico tradizionale. Reggio Emilia, Italy: Diabasis; 2006. pp 7-13.

3. Haruta S, Ueno S, Egawa I, et al. Succession of bacterial and fungal communities during a traditional pot fermentation of rice vinegar assessed by PCR-mediated denaturing gradient gel electrophoresis. Int J Food Microbiol 2006;109:79-87.

4. Ilabaca C, Navarrete P, Mardones P, et al. Application of culture independent molecular methods to evaluate acetic acid bacteria diversity in vinegarmaking process. Int $\mathrm{J}$ Food Microbiol 2008;126:245-9.

5. Nanda K, Taniguchi M, Ujike S, et al. Characterization of acetic acid bacteria in traditional acetic acid fermentation of rice vinegar (komesu) and unpolished rice vinegar (kurosu) produced in Japan. Appl Environ Microbiol 2001;67:986-90.

6. Schuller G, Hertel C, Hammes WP. Gluconacetobacter entanii sp. nov., isolated from submerged high-acid industrial vinegar fermentations. Int J Syst Evol Micr 2000;50:2013-20.

7. Sokollek SJ, Hertel C, Hammes WP. Description of Acetobacter oboediens sp. nov. and Acetobacter pomorum sp. nov., two new species isolated from industrial vinegar fermentation. Int J Syst Bacteriol 1998;48:935-40.

8. De Vero L, Gala E, Gullo M, et al. Application of denaturing gradient gel electrophoresis (DGGE) analysis to evaluate acetic acid bacteria in traditional balsamic vinegar. Food Microbiol 2006;23:809-13.

9. Gullo M, Caggia C, De Vero L, Giudici P. Characterization of acetic acid bacteria in "traditional balsamic vinegar". Int J Food Microbiol 2006;106:209-12.

10. Gullo M, De Vero L, Giudici P. Sucession of selected strains of Acetobacter pasterianus and other acetic acid bacteria in traditional balsamic vinegar. Appl Environ Microbiol 2009;75:2585-89.

11. Entani E, Ohmori S, Masai H, Suzuki KJ. Acetobacter polioxygenes sp. nov., a new species of an acetic acid bacterium useful for producing vinegar with high acidity. J Gen Appl Microbiol 1985;31:47590.

12. Fleet GH. Microorganisms in food ecosystems. Int J Food Microbiol 1999;50:101-17.

13. Giraffa G, Neviani E. DNA-based, culture independent strategies for evaluating microbial communities in food-asociated ecosystems. Int J Food Microbiol 2001;67:19-34.

14. Gonzalez A, Guillamon JM, Mas A, Poblet M. Applications of molecular methods for routine identification of acetic acid bacteria. Int J Food Microbiol 2006;108:141-6.

15. Trcek J. Quick identification of acetic acid bacteria based on nucleotide sequences of the 16S-23S rRNA internal transcribed spacer region and of the $\mathrm{PQQ}$-dependent alcohol dehydrogenase gene. Syst Appl Microbiol 2005;28:735-45.

16. Frueh FW, Noyer-Weidner M. The use of denaturing high performance liquid chromatography (DHPLC) for the analysis of genetic variations: impact for diagnosis and pharmacogenetics. Clin Chem Lab Med 2003;41:452-61.

17. Xiao W, Oefner PJ. Denaturing high-performance liquid chromatography: a review. Hum Mutat 2001;17:439-74.

18. monitoring of microbial populations by denaturing high-performance liquid chromatography. J Microbiol Meth 2005;61:399-411.

19. Goldenberg 0, Herrmann S, Marjoram G, et al. Molecular monitoring of the intestinal flora by denaturing high performance liquid chromatography. J Microbiol Meth 2006;68:94-105.

20. Imirzalioglu C, Hain T, Chakraborty T, Domann. Hidden pathogens uncovered: metagenomic analysis of urinary tract infections. Andrologia 2008;40 66-71.

21. Ercolini D, Frisso G, Mauriello G, et al. Microbial diversity in natural whey cultures used for the production of caciovallo silano PDO cheese. Int J Food Microbiol 2008;124:164-70.

22. Jacinto RC, Gomes BPFA, Desai M, et al. Bacterial examination of endodontic infections by clonal analysis in concert with denaturing high-performance liquid chromatography. Oral Microbiol Immun 2007;22:403-10.

23. Hafez E, Elbestawy E. Molecular characterization of soil microorganisms: effect of industrial pollution on distribution and biodiversity. World J Microbiol Biotechnol 2009;25:215-24.

24. Xu Y, Cui L, Tian C, et al. A multiplex polymerase chain reaction coupled with high-performance liquid chromatography assay for 
simultaneous detection of six foodborne pathogens. Food Control 2012;25:778-83.

25. Hurtle W, Shoemaker D, Henchal E, Norwood D. Denaturing HPLC for identifying bacteria. Biotechniques 2002;33:386-91.

26. Domann E, Hong G, Imirzalioglu C, et al. Culture-independent identification of pathogenic bacteria and polymicrobial infections in the genitourinary tract of renal transplant recipients. J Clin Microbiol 2003;41:5500-10.

27. Sanger F, Coulson AR, Barrell BG, et al. Cloning in single-stranded bacteriophage as an aid to rapid DNA sequencing. J Mol Biol 1980;143:161-78.

28. Altschul SF, Gish W, Miller W, et al. Basic local alignment search tool. J Mol Biol 1990;215:403-10.

29. Jones JB, Lacy GH, Bouzar H, et al. Reclassification of the xanthomonas associated with bacterial spot disease of tomato and pepper. Syst Appl Microbiol 2004;27:755-62.

30. Tribst AAL, Sant'Ana AS, Massaguer PR. Review: microbiological quality and safety of fruit juices: past, present and future perspectives. Crit Rev Microbiol 2009;35:310-39.

31. Costello PJ, Henschke PA. Mousy off-flavor of wine: precursors and biosynthesis of the causative N-heterocycles 2-ethyltetrahydropyridine, 2- acetyltetrahydropyridine, and 2-acetyl-1-pyrroline by Lactobacillus hilgardii DSM 20176. J Agr Food Chem 2002;50:707987.

32. Poblet M, Rozes N, Guillamon JM, Mas A. Identification of acetic acid bacteria by restriction fragment length polymorphism analysis of a PCR-amplified fragment of the gene coding for $16 \mathrm{~S}$ rRNA. Lett Appl Microbiol 2000;31:63-7.

33. Ruiz A, Poblet M, Mas A, Guillamon JM. Identification of acetic acid bacteria by RFPL of PCR-amplified 16S rDNA and 16S-23S rDNA intergenic spacer. Int J Syst Evol Microb 2000;50:1981-7.

34. Sievers M, Alonzo L, Gianotti S, et al. 16S-23S ribosomial RNA spacer regions of Acetobacter europaeus and A. xylinum. tRNA genes and antiterminaton sequences. FEMS Microbiol Lett 1996;142:1438 .

35. Trcek J, Teuber M. Genetic and restriction analysis of the 16S-23S rDNA internal transcribed regions of the acetic acid bacteria. FEMS Microbiol Lett 2000;208:69-75.

36. Andorra I, Landi S, Mas A, et al. Effect of oenological practices on microbial populations using culture-independent techniques. Food Microbiol 2008;25:849-56.

37. López I, Ruiz-Larrea F, Cocolin L, et al. Design and evaluation of PCR primers for analysis of bacterial populations in wine by denaturing gradient gel electrophoresis. Appl Environ Microb 2003;69:6801-7.

38. Du Toit WJ, Pretoris IS, Lonvaud-Funed A. The effect of sulphur dioxide and oxygen on the viability and culturability of a strain of Acetobacer pasterianus and a strain of Brettanomyces brusellensis isolated from wine. J Appl Microbiol 2005;98:862-71.

39. Franke-Whitle IH, O'Shea MG, Leonard GJ, Sly LI. Design, development and use of molecular primers and probes for the detection of Gluconacetobacter species in the pink sugarcane melaybug. Microb Ecol 2005;50:128-39.

40. Gammon KS, Livens S, Pawlosky K, et al. Development of real-time PCR methods for the rapid detection of low concentrations of Gluconobacter and Gluconacetobacter species in a electrolyte replacement drink. Lett Appl Microbiol 2006;44:262-7.

41. Torija MJ, Mateo E, Guillamon JM, Mas A. Identification and quantification of acetic acid bacteria in wine and vinegar by TaqManMGB probes. Food Microbiol 2010;27:257-65. 